\title{
Efficacy of orlistat in the treatment of patients with non-alcoholic fatty liver
}

\author{
Manouchehr Iranparvar Alamdari ${ }^{1}$, Shahram Habibzadeh ${ }^{2}$, Ahad Azami ${ }^{1}$, Babak Shirinzadeh ${ }^{3}$, \\ Roghayeh Aslanian ${ }^{4 *}$, Kiana Yazdanbod ${ }^{5}$
}

\author{
${ }^{1}$ Department of Internal Medicine, ${ }^{2}$ Department of Infectious Disease, Imam Khomeini Hospital, Ardabil University of \\ Medical Science, Ardabil, Iran \\ ${ }^{3}$ Faculty of Medicine, Ardabil University of Medical Science, Ardabil, Iran \\ ${ }^{4}$ Department of Biochemistry, Ghaem Hospital, Ardabil University of Medical Science, Ardabil, Iran \\ ${ }^{5}$ Faculty of Medicine, Shahid Beheshti University of Medical Science, Tehran, Iran
}

Received: 10 November 2019

Revised: 07 January 2020

Accepted: 08 January 2020

\section{*Correspondence:}

Dr. Roghayeh Aslanian,

Email: r.aslaniyan@yahoo.com

Copyright: (C) the author(s), publisher and licensee Medip Academy. This is an open-access article distributed under the terms of the Creative Commons Attribution Non-Commercial License, which permits unrestricted non-commercial use, distribution, and reproduction in any medium, provided the original work is properly cited.

\begin{abstract}
Background: Nonalcoholic fatty liver disease (NAFLD) is a reversible condition of fat accumulation that is associated with liver inflammation and can disrupt the normal activity of the liver. People with a diagnosis of NAFLD have a higher risk of all- cause mortality than the general population. The purpose of the present study was to determine, the efficacy of orlistat in the treatment of patients with NAFLD.

Methods: This semi-experimental study was performed on 45 fatty liver patients of the gastroenterology clinic of Imam Khomeini Hospital in Ardabil city in April 2016 to April 2017. Data was collected by a checklist which included demographic and clinical data such as age, sex, body mass index (BMI), alanine aminotransferase (ALT), aspartate aminotransferase (AST), triglyceride (TG), cholesterol and result of ultrasound before and after orlistat consumption.

Results: The mean decrease in the variables examined was as follows: weight $8.3 \mathrm{~kg}$, BMI $3.5 \mathrm{~kg} / \mathrm{m}^{2}$, ALT $31.6 \mathrm{U} / \mathrm{l}$, AST $18.1 \mathrm{U} / \mathrm{l}$, cholesterol $15.5 \mathrm{mg} / \mathrm{dl}$ and TG $33.1 \mathrm{mg} / \mathrm{dl}$. All of the upper indexes were decreased significantly following received drug.

Conclusions: Orlistat therapy was associated with significant decreases in ALT, AST, TG and cholesterol level. Orlistat is effective in weight loss, body mass index reduction and can be used to treat non-alcoholic fatty liver disease.
\end{abstract}

Keywords: Ardabil, Fatty liver, Orlistat

\section{INTRODUCTION}

Non-alcoholic fatty liver (NAFLD) is a clinicpathological diagnosis in which more than $5 \%$ of hepatocytes demonstrate macrovesicular steatosis in an individual without a significant history of alcohol intake. In recent years NAFLD, the most common form of liver disease, has been recognized as the hepatic manifestation of the metabolic syndrome. ${ }^{1}$ NAFLD occurs across all age groups and ethnicities. The reported prevalence of NAFLD varies widely depending on the population studied and the definition used. The estimated worldwide prevalence of NAFLD ranges from $6.3 \%$ to $33 \%$ with a median of $20 \%$ in the general population, based on a variety of assessment methods. ${ }^{2-4}$ Primary NAFLD is 
related to insulin resistance and thus frequently appears as part of the metabolic changes that accompany obesity, diabetes, and hyperlipidemia. ${ }^{5}$ The usual management of NAFLD includes gradual weight reduction and physical activity, leading to an improvement in serum liver enzyme levels, reduced hepatic fatty infiltration and in some cases a reduced degree of hepatic inflammation and fibrosis. ${ }^{6}$ Although lifestyle modification is sufficient in many patients, resistant cases of NAFLD may require pharmacologic therapy. Candidate medications for the treatment of NAFLD should lead to weight loss, decreased free fatty acid (FFA) flux to the liver, and improved insulin sensitivity, without hepatotoxic adverse effects. $^{7}$ Orlistat, a gastrointestinal lipase inhibitor, is useful in the treatment of obesity and type 2 diabetes mellitus. Gastric and pancreatic lipases are enzymes that play a main role in the digestion of dietary fat. Orlistat, a semisynthetic derivative of lipstatin, is a potent and selective inhibitor of these enzymes; it exerts its effect within the gastrointestinal (GI) tract. Orlistat acts by binding covalently to the serine residue of the active site of gastric and pancreatic lipases. When administered with fat-containing foods, orlistat partially inhibits hydrolysis of triglycerides, thus reducing the subsequent absorption of monoglycerides and FFA. ${ }^{8}$ Therefore, the purpose of this study was to evaluate the effect of orlistat in the treatment of non-alcoholic fatty liver disease in patients of Ardabil city hospital.

\section{Objectives}

The objectives of the present study were to compare the efficacy of orlistat in the treatment of non-alcoholic fatty liver disease in patients with grade II and III fatty liver.

\section{METHODS}

\section{Study design}

This study was semi experimental study.

\section{Procedure}

After approval of the project at the Ethics Committee of Biological Research in Ardebil University, this study was performed on 45 patients with grade II and III fatty liver in ultrasound exam in which were selected by a gastroenterologist from among the patients referred to the Imam Khomeini Hospital in April 2016 to April 2017. An ultrasound examination was carried out at the beginning and at the end of the study by the same person and the same device.

The diet included $100 \mathrm{~kJ} /$ day for ideal body weight, with an emphasis on reduced intake of both fat $(-25 \%$ of daily calories) and simple carbohydrates. all patients were advised to avoid overeating, eating high-fat and highenergy foods during the study and were encouraged to perform physical activity 2 to 3 times a week (30 minutes of walking at 4 to $5 \mathrm{~km} / \mathrm{h}$ ). The nutritionist interviewed all study participants at the time of their monthly clinic visit. The patients received orlistat $(120 \mathrm{mg}$ before lunch and dinner) for three months.

Data was collected by a checklist containing demographical information such as age, sex and weight.

\section{Inclusion criteria}

Non-alcoholic fatty liver patients with grade II and III that approved by an ultrasound exam and patients who signed the consent to diet were included in the study.

\section{Exclusion criteria}

Patients with diabetes mellitus, chronic viral hepatitis, alcoholic fatty liver disease and pregnant women were excluded.

\section{Efficacy measures}

Liver ultrasound condition, body mass index (BMI), serum aspartate and alanine aminotransferase (AST and ALT), cholesterol and triglyceride (TG) levels were assessed at baseline and at the completion of the study.

\section{Statistical analysis}

The collected data were analyzed by SPSS software version 22. Data are presented as mean \pm SD. Paired t-tests were used to evaluate within-group changes from pre and post-treatment. $\mathrm{P}$ value less than $5 \%$ was considered statistically significant.

\section{RESULTS}

Forty-five patients with NAFLD received orlistat. Ninetythree percent of the patients were obese $\left(B M I \geq 30 \mathrm{~kg} / \mathrm{m}^{2}\right)$, $53.3 \%$ of patients were female and the rest were male. The mean age was $45.8 \pm 9.7$ years. Forty-two percent of the patients were 41 to 50 age (Table 1 ).

Table 1: Demographic parameter.

\begin{tabular}{|llll|}
\hline \multirow{2}{*}{ Variables } & & Number & Percentage $(\%)$ \\
\hline \multirow{4}{*}{ Age (in } & Female & 24 & 53.3 \\
\cline { 2 - 4 } years) & Male & 21 & 46.7 \\
\hline & $<30$ & 3 & 6.7 \\
& $31-40$ & 9 & 20 \\
\hline & $41-50$ & 19 & 42.2 \\
\hline & $51-60$ & 10 & 22.2 \\
\hline
\end{tabular}

Following three months therapy with orlistat, body mass index and weight decreased significantly. The mean decrease in the variables examined was as follows: weight loss $8.3 \mathrm{~kg}$, BMI $3.5 \mathrm{~kg} / \mathrm{m}^{2}$, ALT $31.6 \mathrm{U} / 1$, aspartate AST $18.1 \mathrm{U} / \mathrm{l}$, cholesterol $15.5 \mathrm{mg} / \mathrm{dl}$ and $\mathrm{TG} 33.1 \mathrm{mg} / \mathrm{dl}$ (Table 2). At the beginning of the study, all patients had 
grade II or III fatty liver in ultrasound exam. Three months after treatment, $24 \%$ had normal ultrasonography,
$53 \%$ had first grade fatty liver, and $22 \%$ had grade II fatty liver (Table 3).

Table 2: Mean BMI, weight and biochemical tests pre- and post-treatment.

\begin{tabular}{|l|llll|}
\hline Variables & Pre-treatment & Post-treatment & difference & P value \\
\hline BMI in kg/m² (normal, 20-25) & $35.2 \pm 3.4(24-40)$ & $31.8 \pm 3.2(22-37)$ & $3.5 \pm 1.2$ & 0.00 \\
\hline Weight in kg & $100 \pm 14.8(75-138)$ & $91.8 \pm 14.3(69-116)$ & $8.3 \pm 3.4$ & 0.00 \\
\hline $\begin{array}{l}\text { Triglyceride level in mg/dl } \\
\text { (normal, 50-175) }\end{array}$ & $258.5 \pm 68.1(94-327)$ & $225.3 \pm 74.5(29-313)$ & $33.1 \pm 40.1$ & 0.00 \\
\hline $\begin{array}{l}\text { Cholesterol level in mg/dl } \\
\text { (normal, 150-200) }\end{array}$ & $222.4 \pm 61.6(146-317)$ & $206.8 \pm 61.2(128-312)$ & $15.5 \pm 13.3$ & 0.00 \\
\hline ALT level in U/l (normal, 5-39) & $73.6 \pm 33(26-216)$ & $42 \pm 26.2(5-154)$ & $31.6 \pm 13.7$ & 0.00 \\
\hline AST level in U/l (normal, 5-40) & $41.5 \pm 14.8(19-75)$ & $23.4 \pm 13.4(2-57)$ & $18.1 \pm 5.8$ & 0.00 \\
\hline
\end{tabular}

Note: For all variables, data are presented as mean \pm SD, with the range in parentheses.

Table 3: Frequency of NAFLD grade in pre- and post-treatment.

\begin{tabular}{|c|c|c|c|c|c|c|c|c|c|}
\hline \multirow{3}{*}{ Time of study } & \multicolumn{8}{|c|}{ Fatty liver grade } & \multirow{3}{*}{ P value } \\
\hline & \multicolumn{2}{|c|}{3} & \multicolumn{2}{|l|}{2} & \multicolumn{2}{|l|}{1} & \multicolumn{2}{|l|}{0} & \\
\hline & $\mathbf{N}$ & $\%$ & $\mathbf{N}$ & $\%$ & $\mathbf{N}$ & $\%$ & $\mathbf{N}$ & $\%$ & \\
\hline Base line & 23 & 51.1 & 22 & 48.9 & - & - & - & - & רח0 \\
\hline End of study & - & - & 10 & 22.2 & 24 & 53.3 & 11 & 24.4 & 0.02 \\
\hline
\end{tabular}

\section{DISCUSSION}

The prevalence of NAFLD is rapidly increasing worldwide along with the increase in obesity and type 2 diabetes. ${ }^{9}$ Studies show that NAFLD is often associated with insulin resistance, obesity, diabetes mellitus, hyperlipidemia, visceral adiposity and other cardiometabolic diseases. ${ }^{1,10-12}$

Orlistat, a reversible inhibitor of gastric and pancreatic lipases, has been approved by the FDA for weight loss. It is not absorbed into the circulation and is mainly excreted unchanged in the faces. Data suggest that when orlistat combined with dietary counseling, approximately $40 \%$ of treated patients for one year were able to lose up to $10 \%$ of their body weight. ${ }^{13}$ Lipase inhibition by orlistat prevents the absorption of approximately $30 \%$ of energy from fat. ${ }^{14,15}$ Orlistat, as an anti obesity drug, reduces lipid levels following a high-fat meal. A study by Gabriel et al identified that administration of orlistat suppressed the postprandial rise of TG levels in healthy adult volunteers following consumption of meals with $50 \%$ fats. ${ }^{16}$

The present study showed that patients lose up $8.3 \mathrm{~kg}$ of their body weight after the use of orlistat and their body mass index decreased significantly too. In a study by Smith et al results showed that orlistat was an effective drug to weight loss and reducing metabolic risk factors associated with abdominal obesity. ${ }^{17}$ Other studies showed that treatment with orlistat reduced weight and improved hyperglycemia in diabetic overweight patients. ${ }^{14,18}$ Finer et al in a study on obese patients for one-year, showed that Orlistat group had lower waist circumference than the placebo group and weight loss in Orlistat group was $14 \%$ more than the placebo group. ${ }^{19} \mathrm{In}$ the study by Zelber-Sagi et al Weight loss mean with orlistat treatment was $7.7 \mathrm{~kg}$, and in the study by Harrison et al Orlistat was associated with a significant reduction in weight, HbA1c, ALT and AST. ${ }^{7,13}$ In meta-analysis by Wang et al the efficacy and safety of orlistat in the treatment of NAFLD and improvements were observed in levels of Alanine aminotransferase, aspartate aminotransferase, gamma-glut amyl transpeptidase and triglycerides. They suggested that orlistat could serve as a therapeutic drug in improving biochemical indicators of liver damage, suggesting a novel palliative drug for the treatment of NAFLD. ${ }^{20}$

\section{CONCLUSION}

Significant decreases in ALT, AST, TG and cholesterol levels were observed following Orlistat therapy and the drug is effective in weight loss and body mass index reduction. It seems that orlistat can be used in treatment of non-alcoholic fatty liver disease. Using an antioxidant such as vitamin E along with orlistat may also help to improve the tissues damages in NAFLD. A clinical trial is recommended using the combination of the two drugs.

\section{ACKNOWLEDGEMENTS}

The results of this study financially supported by Ardabil University of Medical Science and authors would like to thanks all participants in the study.

\section{Funding: No funding sources}

Conflict of interest: None declared

Ethical approval: The study was approved by the Institutional Ethics Committee

\section{REFERENCES}

1. Angulo P. Nonalcoholic fatty liver disease. N Engl J Med. 2002;346:1221-31. 
2. Browning JD, Szczepaniak LS, Dobbins R, Nuremberg P, Horton JD, Cohen JC, et al. Prevalence of hepatic steatosis in an urban population in the United States: impact of ethnicity. Hepatology. 2004;40:1387-95.

3. Nomura H, Kashiwagi S, Hayashi J, Kajiyama W, Tani S, Goto M. Prevalence of fatty liver in a general population of Okinawa, Japan. Japanese J Med. 1988;27:142-9.

4. Chalasani N, Younossi Z, Lavine JE, Diehl AM, Brunt EM, Cusi K, et al. The diagnosis and management of non-alcoholic fatty liver disease: Practice Guideline by the American Association for the Study of Liver Diseases, American College of Gastroenterology, and the American Gastroenterological Association. Hepatology. 2012;55:2005-23.

5. Adams LA, Angulo P. Treatment of non-alcoholic fatty liver disease. Postgraduate Med J. 2006;82:315 22.

6. Dixon JB, Bhathal PS, Hughes NR, O'Brien PE. Nonalcoholic fatty liver disease: improvement in liver histological analysis with weight loss. Hepatology. 2004;39:1647-54.

7. Zelber-Sagi S, Kessler A, Brazowsky E, Webb M, Lurie Y, Santo M, et al. A double-blind randomized placebo-controlled trial of orlistat for the treatment of nonalcoholic fatty liver disease. Clinical Gastroenterology and Hepatology. 2006;46:39-44.

8. Guerciolini R. Mode of action of orlistat. International journal of obesity and related metabolic disorders. J Int Association Study Obesity. 1997;21:12-23.

9. Björnsson E, Angulo P. Non-alcoholic fatty liver disease. Scandinavian J Gastroenterol. 2007;42:102330 .

10. Lonardo A, Loria P. NAFLD and cardiovascular risk: direct evidence for the tale of two ages. The American J Gastroenterol. 2009;104:1851.

11. Falck-Ytter Y, Younossi ZM, Marchesini G, McCullough AJ. Clinical features and natural history of nonalcoholic steatosis syndromes. Seminars Liver Dis. 2001;21:17-26.

12. Bellentani S, Scaglioni F, Marino M, Bedogni G. Epidemiology of non-alcoholic fatty liver disease. Digest Dis. 2010;28:155-61.
13. Harrison SA, Fincke C, Helinski D, Torgerson S, Hayashi P. A pilot study of orlistat treatment in obese, non-alcoholic steatohepatitis patients. Alimentary Pharmacol Therap. 2004;20:623-8.

14. Davidson MH, Hauptman J, DiGirolamo M, Foreyt JP, Halsted CH, Heber D, et al. Weight control and risk factor reduction in obese subjects treated for 2 years with orlistat: a randomized controlled trial. JAMA. 1999;281:235-42.

15. Grundy S.M. Hypertriglyceridemia, atherogenic dyslipidemia, and the metabolic syndrome. The American J Cardiol. 1998;81:18-25.

16. Gabriel FS, Samson CE, Abejuela ZR, Sicat-Gabriel PR, Sumpio JP, Zacarias MB, et al. Postprandial effect of orlistat on the peaking of lipid level after sequential high fat meals. Int J Endocrinol Metabol. 2012; 10:458.

17. Smith SR, Stenlof KS, Greenway FL, McHutchison J, Schwartz SM, Dev VB, et al. Orlistat $60 \mathrm{mg}$ Reduces Visceral Adipose Tissue: A 24-Week Randomized, Placebo-Controlled, Multicenter Trial. Obesity. 2011;19:1796-803.

18. Hanefeld M, Sachse G. The effects of orlistat on body weight and glycaemic control in overweight patients with type 2 diabetes: a randomized, placebocontrolled trial. Diabetes Obes Metabol. 2002;4:41523.

19. Finer N, James WP, Kopelman PG, Lean ME, Williams G. One-year treatment of obesity: a randomized, double-blind, placebo-controlled, multicentre study of orlistat, a gastrointestinal lipase inhibitor. Int J Obes. 2000;24:306.

20. Wang H, Wang L, Cheng Y, Xia Z, Liao Y, Cao J. Efficacy of orlistat in non-alcoholic fatty liver disease: A systematic review and meta-analysis. Biomed Rep. 2018;9:90-6.

Cite this article as: Alamdari MI, Habibzadeh S, Azami A, Shirinzadeh B, Aslanian R, Yazdanbod K. Efficacy of orlistat in the treatment of patients with non-alcoholic fatty liver. Int J Basic Clin Pharmacol 2020;9:296-9. 